\title{
An Analysis of Coaches' Perceptions of Inappropriate Coaching Behaviors
}

\begin{abstract}
By Brad Strand"
The use of inappropriate coaching behaviors has been an ongoing concern for many years. However, not yet well researched is the use of inappropriate and bullying behaviors by coaches toward student-athletes. The purpose of this study was aimed at gathering relevant information on coaches' use of inappropriate behaviors towards athletes, as reported by coaches. Participants for this study included 488 public/private school sport coaches, males $(N=332)$ and females $(N=153)$, from eight states. Data were gathered via an on-line survey in which participants identified if they had engaged in any of 22 listed actions among three types of bullying (physical, relational, verbal). Participants identified three actions ('poking fun at an athlete', 'embarrassed an athlete in front of others', and 'name calling without hurtful intent') as having been done by at least $30 \%$ of them. In summary, most actions were reported to have not been used by most coaches, three-fourths of the actions were considered inappropriate, and less than half were considered bullying.
\end{abstract}

Keywords: coaching, bullying, sports

\section{Introduction}

In 2015, Wolff published an article in Sport Illustrated titled, "Is the era of abusive college coaches finally coming to an end"? Within the article the author presented a list of major college coaches who had been accused of abusing athletes. The list included Bobby Knight at Indiana, Tim Beckman at the University of Illinois, Greg Winslow at the University of Utah, and Erin Layton at the University of Rhode Island. The story came in the aftermath of video showing Mike Rice of Rutgers physically and mentally abusing his basketball players. Has much changed since then? One would hope so, but just in the past year basketball coaches at Detroit Mercy (Wimbley and Komer 2021), Texas Tech (Pao 2020), and PurdueFort Wayne (Benbow 2021) have been accused of abusive behavior towards their athletes.

Bullying, abuse, and inappropriate behavior have long been a topic of emphasis in k-12 school settings (American Educational Research Association 2013). However, does that emphasis carry over to school sponsored extra-curricular activities, e.g., athletics? And if so, does it only focus on the behavior of students or are coaches included too? Although numerous studies have reported on positive youth development through sport (Fraser-Thomas et al. 2005, Turnnidge et al. 2014, Vella et al. 2011, Vierimaa et al. 2012), the athlete-coach relationship (Dominteanu 2011, Jowett and Cockerill 2003, Poczwardowski et al. 2006), and perceived poor coaching (Gearity 2012, Gearity and Thompson 2011); few studies

*Professor, North Dakota State University, USA. 
have actually investigated inappropriate coaching practices in high school sport settings (Alexander et al. 2011, Shields et al. 2005, Strand et al. 2017, Swigonski et al. 2014, Yukhymenko-Lescroart et al. 2015), and for the most part, these studies are from the athletes' perspective.

Coaches interact with their athletes on a daily basis in practice, and in many instances, throughout the school day. These in-school interactions involve talking about the team, other athletes, opponents, practices, past games, and upcoming games in a somewhat equal social setting. When the school bell rings ending the school day, the teacher becomes a coach and the student an athlete. Both individuals assume different roles in different settings. Interactions and communication take on different meanings in the context of practice and games. What a teacher/coach says jokingly in the hallway to a student/athlete is easily interpreted differently on the practice field or court. Many athletes validate themselves through their sport performance and this becomes their identity (Burns et al. 2012, Ronkainen et al. 2016, Ronkainen and Ryba 2019). Insensitive comments in practice settings carry a lot more weight than those said outside the confines of practice, and athletes respond differently to those comments.

With that background as a preface, this study was aimed at gathering relevant information on coaches' use of inappropriate behaviors towards athletes as reported by coaches. The following research questions guided the study:

- As a coach, have you ever done the identified action to an athlete?

- Do you think this is an inappropriate coaching action?

- Do you consider this action bullying?

\section{Methods}

\section{Participants}

Members of state coaches associations in eight midwestern states completed a 22-item survey that included a listing of actions described as bullying. Potential subjects received an email inviting them to participate in the survey. The email was distributed to coaches via an email sent from an identified colleague within each of the state associations. The email included an informed consent and a link to the survey. Data were collected via a Qualtrics survey. In additional to the usual demographic information, participants were asked to indicate if; 1) if they had ever done this action to an athlete, 2) if they think this is an inappropriate coaching action, 3) if they consider this action bullying, and, 4) if they had stopped doing the action when they knew it was inappropriate.

Participants were 488 public/private school coaches, males $(N=332,68.5 \%)$ and females $(N=153,31.5 \%)$ from eight states (MO, NE, ND, MN, KS, IA, SD, MS). The ethnic composition of the sample was largely White/Caucasian (92.3\%), followed by Black American (4.3\%), Hispanic (0.4\%), Native American (1.4\%), Asian/Pacific Islander (0.2\%), and Multiple ethnicity/other (1.0\%). One-half of the participants had earned a graduate degree. By age, 14.9\% were aged 20-30, 22.6\% were aged $31-40,25.9 \%$ were aged $41-50,25.0 \%$ were aged $51-60,9.4 \%$ were 
aged 61-70, and 2.0\% were older than 70. By degree, every participant had obtained a high school degree or GRE; $99.6 \%$ had attended some college; $93.8 \%$ had obtained a BS degree; and $47.2 \%$ had earned a graduate degree. By occupation, $78.4 \%$ were employed as school teachers.

\section{Measures}

Table 1. Coach Behaviors

\begin{tabular}{|c|c|c|c|}
\hline Coach Behavior with Type and Degree & $\begin{array}{l}\text { Have you } \\
\text { ever done } \\
\text { this to an } \\
\text { athlete? }\end{array}$ & $\begin{array}{l}\text { Do you think this } \\
\text { is an } \\
\text { inappropriate } \\
\text { coaching action? }\end{array}$ & $\begin{array}{l}\text { Do you } \\
\text { consider } \\
\text { this } \\
\text { bullying? }\end{array}$ \\
\hline $\begin{array}{l}\text { 1. Hit, slapped or heckled an athlete } \\
\text { with intent to hurt }(\mathrm{P}, \mathrm{M})\end{array}$ & $2.3 \%$ & $82.4 \%$ & $64.8 \%$ \\
\hline 2. Threw something at an athlete $(\mathrm{P}, \mathrm{M})$ & $9.8 \%$ & $77.3 \%$ & $45.3 \%$ \\
\hline $\begin{array}{l}\text { 3. Threw something at an athlete with intent } \\
\text { to hurt }(\mathrm{P}, \mathrm{Mo})\end{array}$ & $0.8 \%$ & $80.1 \%$ & $60.9 \%$ \\
\hline 4. Struck an athlete with equipment $(\mathrm{P}, \mathrm{Mo})$ & $3.7 \%$ & $78.9 \%$ & $54.3 \%$ \\
\hline $\begin{array}{l}\text { 5. Physical violence to deliberately inflict } \\
\text { pain on an athlete }(\mathrm{P}, \mathrm{S})\end{array}$ & $1.0 \%$ & $82.0 \%$ & $62.1 \%$ \\
\hline 6. Locked an athlete in a room $(\mathrm{P}, \mathrm{S})$ & $0.8 \%$ & $81.6 \%$ & $60.5 \%$ \\
\hline $\begin{array}{l}\text { 7. Inappropriate unwanted touching towards } \\
\text { an athlete }(\mathrm{P}, \mathrm{S})\end{array}$ & $1.6 \%$ & $82.0 \%$ & $49.4 \%$ \\
\hline $\begin{array}{l}\text { 8. Critical comments meant to hurt an athlete } \\
(\mathrm{R}, \mathrm{M})\end{array}$ & $6.6 \%$ & $77.0 \%$ & $56.1 \%$ \\
\hline 9. Dirty look meant to hurt an athlete (R, M) & $13.7 \%$ & $70.3 \%$ & $43.0 \%$ \\
\hline $\begin{array}{l}\text { 10. Embarrassed an athlete in front of others } \\
(\mathrm{R}, \mathrm{Mo})\end{array}$ & $34.0 \%$ & $61.3 \%$ & $41.6 \%$ \\
\hline 11. Set an athlete up to look foolish (R, Mo) & $7.6 \%$ & $75.8 \%$ & $49.2 \%$ \\
\hline $\begin{array}{l}\text { 12. Mild ethnic slurs towards an athlete (R, } \\
\text { Mo) }\end{array}$ & $2.0 \%$ & $80.9 \%$ & $57.4 \%$ \\
\hline $\begin{array}{l}\text { 13. Hurtful ethnic slurs towards an athlete } \\
(\mathrm{R}, \mathrm{S})\end{array}$ & $1.0 \%$ & $81.1 \%$ & $60.2 \%$ \\
\hline 14. Shunning an athlete from the team $(\mathrm{R}, \mathrm{S})$ & $5.7 \%$ & $75.0 \%$ & $50.6 \%$ \\
\hline $\begin{array}{l}\text { 15. Obscene gestures toward an athlete (R, } \\
\text { Mo) }\end{array}$ & $1.8 \%$ & $81.1 \%$ & $51.8 \%$ \\
\hline 16. Poked fun at an athlete $(\mathrm{V}, \mathrm{M})$ & $44.9 \%$ & $43.0 \%$ & $25.4 \%$ \\
\hline $\begin{array}{l}\text { 17. Inappropriate language towards an } \\
\text { athlete; comments on sexual preferences (V, } \\
\mathrm{M})\end{array}$ & $3.1 \%$ & $80.5 \%$ & $51.6 \%$ \\
\hline $\begin{array}{l}\text { 18. Name calling without hurtful intent (V, } \\
\text { M) }\end{array}$ & $30.9 \%$ & $50.4 \%$ & $26.2 \%$ \\
\hline 19. Name calling with hurtful intent $(\mathrm{V}, \mathrm{Mo})$ & $1.6 \%$ & $81.1 \%$ & $61.3 \%$ \\
\hline $\begin{array}{l}\text { 20. Verbal threats of aggression towards an } \\
\text { athlete }(\mathrm{V}, \mathrm{Mo})\end{array}$ & $2.5 \%$ & $79.7 \%$ & $58.8 \%$ \\
\hline $\begin{array}{l}\text { 21. Use of nickname when asked not to (V, } \\
\text { M) }\end{array}$ & $6.1 \%$ & $74.8 \%$ & $45.1 \%$ \\
\hline 22. Taunting at athlete $(\mathrm{V}, \mathrm{Mo})$ & $3.3 \%$ & $78.7 \%$ & $54.5 \%$ \\
\hline
\end{tabular}

Type: Physical (P), Relational (R), Verbal (V).

Degree: Mild (M), Moderate (Mo), Severe (S). 
The survey used for this study contained eight questions. Question one asked participants to review the (twenty-two) actions shown in Table 1 and indicate if: 1) if they had ever done this to an athlete, 2) if they think this is an inappropriate coaching action, and 3) if they consider this action bullying. As seen in the table, each action can be further defined as physical, verbal, or relational, and as mild, moderate, or severe.

The twenty-two items that were evaluated came from an inventory titled "Bully-Spotter: What is Bullying in Sports?" (Haber 2004). Haber's original Bully Spotter included fifty-three items categorized as physical, relational, or verbal bullying and then as mild, moderate, or severe in nature. The Bully Spotter was initially designed to be used to identify student-to-student bullying. For our purposes, we elected not to include all the items because many are student-tostudent actions, for example, towel snapping, taking possessions (clothing, equipment, etc.), blame-placing, and gossiping. This inventory has been used in previous research (Strand et al. 2017). Demographic questions asked about gender, years of coaching experience, age, highest degree or level of school completed, racial background, if they were a k-12 teacher in addition to coaching, and the state in which they coached.

\section{Procedures}

Upon University Institutional Review Board approval, the questionnaire was formatted into the online data collection system known as Qualtrics. Colleagues in eight different states were asked to email the survey invitation to coaches in their respective states. All individuals who participated were current coaches. Each participant receiving the email was initially invited to participate in the study by opening a link that informed the recipient of the purpose of the study and content. In this same document, each participant was given the option to proceed with the survey by clicking a link to the actual survey. Clicking the link also indicated implied consent to participate in the study. The Qualtrics document was designed to accept only one response from each participant.

\section{Data Analysis}

All data were initially collected via Qualtrics. At the end of the data collection period, data were transferred to Statistical Package for the Social Sciences (SPSS, version 27) for further analysis. The methods applied were means and frequency distributions, cross tabulations, Pearson correlation tests, and Chi-square tests.

\section{Results}

Four hundred and eighty-five (485) coaches completed the survey. Table 1 reports the percentage of coaches who reported they had done the described action to an athlete, who think the action is inappropriate, and who think the action is bullying. Statistical analysis was conducted based on gender (male, female), years 
of coaching experience (1-10, 11-20, 21-30, 30+), degree (no degree, BS degree, graduate degree), and occupation (school teacher, not a school teacher).

\section{Have you ever done this to an Athlete?}

Three actions were identified by participants as having been done by at least $30 \%$ of them. The most frequently reported action of a coach to an athlete was 'poking fun at an athlete' (44.9\%). The second most frequently reported action of a coach to an athlete was 'embarrassed an athlete in front of others' (34.0\%). The third action with more than $30 \%$ reporting they had done was 'name calling without hurtful intent'. Of the 22 actions, less than $10 \%$ of the participants reported they 'had done this action' to an athlete for 19 of the actions; and more specifically, less than $5 \%$ of the participants reported they had done this to an athlete for 13 of the actions.

Fishers exact test found significant differences by gender for five of the actions. For each of these actions, male responses were significantly higher than those of females: 'struck an athlete with equipment' ( $\mathrm{p}=0.043)$; 'embarrassed an athlete in front of others' $(\mathrm{p}=0.000)$; 'set an athlete up to look foolish' $(\mathrm{p}=0.024)$; 'poked fun at an athlete' $(\mathrm{p}=0.004)$; and 'name calling with hurtful intent' $(\mathrm{p}=0.000)$. An ANOVA found no statistical significance differences based on years of coaching experience. Based on degree, a Chi Square revealed statistical difference for two actions, 'embarrassed at athlete in front of others' $(\mathrm{p}=0.004)$ and 'name calling with hurtful intent' $(p=0.033)$. In both cases, participants with no degree reported doing these actions more than those with a college degree. Based on occupation, a Chi Square found significant difference for one statement, 'embarrassed an athlete in front of others' $(\mathrm{p}=0.004)$. Results revealed that teachers were more likely to do this than non-teachers.

\section{Do you think this is an Inappropriate Coaching Action?}

Approximately 55-60\% of participants considered 21 of the 22 actions as an inappropriate coaching action. The only action with less than $50 \%$ support was 'poked fun at an athlete' with $43 \%$ who indicated they thought this action was inappropriate. For 10 of the actions, over $80 \%$ of participants indicated they thought the action was an inappropriate coaching action.

Fishers exact test found significant differences by gender for one of the actions, 'struck an athlete with a piece of equipment' $(\mathrm{p}=0.031)$. Females were more likely to think this was inappropriate than males. An ANOVA found statistical significance based on years of coaching experience for two actions, 'inappropriate unwanted touching towards an athlete' $(\mathrm{p}=0.044)$ and 'verbal threats of aggression towards an athlete' $(\mathrm{p}=0.028)$. For both actions, participants with $30+$ years of experience differed from those with 11-20 years of experience ( $\mathrm{p}=0.045$ and $\mathrm{p}=0.036$, respectively). In both instances, the more experienced participants were less likely to think the action was inappropriate. No significant differences were noted based on degree and occupation. 
Do you consider this Bullying?

The percent of participants who considered the actions as bullying ranged from $25.4 \%$ for 'poking fun at an athlete' to $64.8 \%$ for 'hit, slapped, or heckled an athlete with intent to hurt'. For all of the actions considered, barely half of participants indicated they considered the action bullying for 14 of the statements. For the other eight statements, less than half considered the action as bulling.

Fishers exact test found significant differences by gender for two of the actions. For each of these actions, females were more likely to identify the action as bullying: 'shunning an athlete from the team' $(\mathrm{p}=0.016)$ and, 'inappropriate language towards an athlete' $(\mathrm{p}=0.034)$. An ANOVA found statistical significance differences based on years of coaching experience for three of the actions: 'mild ethnic slurs toward an athlete' ( $\mathrm{p}=0.031$ ), 'hurtful ethnic slurs towards an athlete' $(\mathrm{p}=0.037)$, and 'name calling with hurtful intent' $(\mathrm{p}=0.041)$. In all three instances, the differences occurred between participants with 1-10 and 30+ years of experience. Participants with $30+$ years of experience were less likely to consider the action as bullying ( $\mathrm{p}=0.024, \mathrm{p}=0.024$, and $\mathrm{p}=0.023$, respectively). Based on occupation, a Chi Square found significant difference for five statements, 'threw something at an athlete' $(p=0.041)$, 'dirty look meant to hurt an athlete' $(p=0.012)$, 'embarrassed an athlete in front of others' $(\mathrm{p}=0.015)$, 'name calling without hurtful intent' $(p=0.014)$, and 'verbal threats of aggression towards an athlete' $(p=0.043)$. Results revealed that teachers were more likely than non-teachers to consider the first two mentioned actions as bullying while nonteachers were more likely to identify the other three actions as bullying. No significant differences were noted based on degree.

\section{Participants' Comments about Actions}

For each of the actions, participants were offered an opportunity to provide comments. For most of the actions, no comments were provided or a simple "no', "never". However, for some of the actions, participants provided more extensive comments; often providing clarification or perhaps justification for doing the action. In addition, the most comments were provided for the actions that were identified as having occurred most often. What follows are examples of comments for select actions.

\section{Poking Fun at an Athlete}

Coaches who commented said their poking fun at an athlete was just that, fun. One coach said, "Sometimes you have to be able to laugh at yourself when you goof up. So in this instance, I've probably made fun of an athlete (and myself) when he (or myself) has done something silly. I would not do this to intentionally hurt an individual." Another said, "all in good fun, was ok with athlete." A third said, "Knowing your athletes is important...having fun is important too....humor is contagious as long as you do not hurt the athlete." One said it was used as means to relieve tension and another said it was only used with athletes that he had a great rapport with." 
A number of coaches did talk about the fine line of going too far with poking fun at athletes. One said, "If it gets out of hand and is repeated quite a bit, this would be bullying. However, I think poking fun at them in the right way can get their attention." Another said, "There is a line here. It is hard to define where it goes from showing acceptance (friendly ribbing) and where it is hurtful. Sometimes it is well intended but misinterpreted. If I felt I was misinterpreted I would apologize and attempt to make amends."

One coach excused it by saying, "Never meant to hurt feelings. Any new person that joins my team, I inform them that I am sarcastic."

\section{Struck an Athlete with Equipment/Thrown Anything at an Athlete}

The coaches who commented on striking an athlete with equipment generally did so a part of a drill or just having fun. One participant stated, "hitting them with whistle on helmet, messing around, the kids know this". Another said, "Depends. We use blocking pads and other devices to simulate game atmosphere. Sometimes we make things difficult, but we never do it with an intent to harm or hurt an athlete." A third said, "Basketball drills where we work on finishing a layup through contact. Student gets "hit" with a blocking pad."

The coaches who commented on throwing anything at an athlete, responded they had done this, "in a joking manner", "to get their attention", "to focus attention", "in good fun", and "only as a training tool".

\section{Embarrassed an Athlete in Front of Others}

For this action, coaches explained it as something that can be used to draw attention to inappropriate athlete behavior or to help change behavior. For example, "Sometimes this is an effective way to get the athlete's attention. However, if done repeatedly and with malicious intent, it would constitute bullying." Another said, "I have called an athlete out regarding inappropriate behavior he was publicly exhibiting in front of the team at that moment. In, doing so the athlete was likely embarrassed by the attention it drew." A third said, "This is something I used to do to invoke change, but I realize that one on one is much more effective and better. Correction is still sometimes done, but embarrassment is never the goal".

Two coaches said they couldn't control what embarrassed an athlete. One stated, "Whether or not the athlete is embarrassed is only something the athlete knows and can control, I have called out athletes for lack of effort, failure to listen, or for letting down other athletes -- I would assume that at times some have been embarrassed" Another stated, "Yes, this is different for each kid. What embarrasses one athlete, might not another. Intention is an embarrass but a side effect." One coach said that he had done this, but only a few times on purpose, and when he realized he had embarrassed an athlete, which wasn't his intention, he would apologize for his actions.

Set an Athlete up to Look Foolish

Coaches tended to explain this action as something they did to help an athlete(s) better understand that what they were doing was incorrect. One coach 
said he set an athlete up to look foolish, "only when this athlete was acting in a way that they were better than others so to set up a scenario where they would realize they were not any better than the others." Similarly, another said, "Sometimes players feel as though they have a technique that may work out. Rather than correct it, we let them try it to see it fail. It makes them realize that there is a different way. Making them look foolish on purpose to demean them is bullying."

A third said, "If the athlete has been cocky, I try to have them not as cocky." A fourth said, making them look foolish, "sets the tone when there is a player who wants to do his/her own thing and tries to get other players to follow, but it needs to be explained to the whole team as to why that happened and explain the role of the coach and roles of the athletes"

\section{Name Calling without Hurtful Intent}

Comments in reference to this action are similar to those mentioned in poking fun at an athlete. Many coaches commented they did this but it was meant to be in fun, "Yes in jokes, it is a give and take" and "possibly in a playful/teasing manner". Others commented on the use of nicknames, "If your team culture is one where nicknames are okay, then this would be okay.", "We have team nick names from time to time. For example, a kid's name might be John David and we call him JD. Or a kid maybe is particularly skilled at hill running and we might call him the HB short for Hill Beast.", and "We have nicknames for everyone. So long as they are not offensive or hurtful." One coach commented, "Again, the types of names are critical in how they will be perceived, along with the tone, context, and body language. Calling a player, a "silly goose" is much more innocent and playful than a more demeaning remark"

\section{Dirty Look Meant to Hurt an Athlete}

One participant said, "I do not know what would constitute a "dirty look", but I have looked at athletes disapprovingly for inappropriate conduct on their part." Another said, "I've given frustrated looks when my athletes miss a sign or do something we have just talked about not doing. It was not meant to hurt an athlete but it very well could have hurt their feelings."

\section{Discussion}

Although the number of participants reporting to have done the listed actions appears low for most of the actions, the percentage of participants reporting to have done some of the actions is concerning. In particular, 'having thrown something at an athlete', 'embarrassing an athlete in front of others', 'dirty looks meant to hurt an athlete', 'poking fun at an athlete', and 'name calling without hurtful intent'. All five of these actions have been described as mild forms of bullying (Haber 2004), with one of them being physical and two each being relational and verbal. 
When considering if an action is an inappropriate coaching action, three actions stand out: 'embarrassed an athlete in front of others', 'poking fun at an athlete', and 'name calling without hurtful intent'. As all three of these were identified as actions participants had done toward athletes, it makes sense that the participants would not consider them as inappropriate. Similarly, these three items were also indicated as not considered bullying by most of the participants.

For three of the five actions listed above, male participants reported having done so more than female participants. Two of these actions, 'embarrassed an athlete' and 'name calling', were more likely to be done by participants without college degrees and one of them, 'embarrassed an athlete', by a teacher. Although there were no differences in doing the actions, as based on years of experience, two significant differences noted by years of experience were identified when considering if an action is inappropriate and three differences when considering the action as bullying. In all five instances, participants with 30+ years of experience were less likely to consider the action as an inappropriate coaching action and as bullying.

When considering if one had ever done an action, only two differences were found based on level of earned degree. Participants without a degree were more likely to 'embarrass an athlete in front of others' and 'call someone a name with hurtful intent'. And finally, considering if one is a teacher or nonteacher, one difference was found in doing an action, that being 'embarrassed an athlete in front of others' with nonteachers doing it less than teachers and five differences in relation to considering an action as bulling.

Previous work on inappropriate coaching indicates great differences in the reporting of actions having been done by coaches, as reported by athletes (Strand et al. 2017). Using the same 22 actions as listed in this study, Strand et al. surveyed 920 college students on their perceptions of actions by their former coaches. As might be expected, athletes were more likely to report having had a coach do one the actions to them than a coach would self-report. For example, looking at the items mentioned as concerns earlier in this section, $16.1 \%$ of athletes compared to $9.8 \%$ of coaches reported having had 'something thrown at them' and $19.7 \%$ of athletes compared to $13.7 \%$ of coaches reported the 'coach used dirty looks meant to hurt'.

Two questions remain, first, are these actions inappropriate, and second, are they bullying. From a coaches' perspective, approximately three-fourths of coaches in this study indicated the actions were inappropriate, and approximately half indicated they considered the action as bullying.

Based on these findings, on one hand it is easy to understand how some coaches might be accused of inappropriate or abusive practices. If one does not think an action is inappropriate or bullying, there is no reason for a coach not to use that action when interacting with athletes. For many coaches, their coaching practices mirror that of coaches for whom they had previously played (Moen et al. 2015). Unfortunately for those coaches, what was once accepted as allowable is no longer accepted.

On the other hand, it is hard to understand how anyone coaching in today's society is not culturally or socially aware enough to recognize what is acceptable 
and unacceptable. Is it perhaps that some coaches believe they have immunity for their actions because they are simply coaching and what happens during practice stays within the bounds of the practice field? As reported in Strand et al. (2017), coaches use any number of excuses to rationalize their actions including moral justification, backhanded apology, it could have been worse comparison, escalation of stakes, mental toughness argument, secrecy and building team culture.

The allegations filed against the basketball coach at Purdue-Fort Wayne included: the coach mocked players for depression, forced them to play through injuries, pressured them to go on medications, such as antidepressants, called them out of shape and fat, withheld medical care, denied them food as punishment, did not allow players to see a psychologist without a coaching staff present and once told a player to "get over it" after a sexual assault (Benbow 2021). The coach responded to the allegations with, "While I respect these women and their right to speak out, I deny that I have ever physically, mentally or emotionally abused any player in our program."

At Texas Tech, players accused their coaches of punishing players whose heart rates dropped below $90 \%$ of capacity during playing time for more than two minutes, of calling them "fat pigs' and "disgusting", of being mocked for weight and exhibiting signs of depression, and sexual harassment (Pao 2020). The coach responded with, "Our administration and my staff believe in the way we are building and turning this program around here. Our student athletes are developing a disciplined approach both on and off the court. I want our students, fans and alumni to know we are committed to winning championships at Texas Tech and doing it the right way through hard work, accountability and fierce determination."

The players at Detroit Mercy accused their coach of creating an environment "so toxic and draining that player's made comments in the locker room about having suicidal thoughts as well as purposely injuring themselves to avoid potentially having to deal the coaches' belittling and emotional abuse." (Solari 2021). Coach Gilbert responded with, "it completely blindsided me, in our opinion, we have a normal, healthy Division I atmosphere and environment". She further stated, "I came here to be a part of change, positive change, to help change the culture. To help chart a path to national prominence, to impact these women positively. I'm here to coach, to teach, to develop them and to grow them into strong, empowered women". Not surprisingly, all 14 players from the 2020-2021 roster either left the program or have been told they can no longer play basketball.

Obviously these three coaches fail to take responsibility for their actions and are in fact, justifying their means to an end. And in all reality, it does not really matter if a coach thinks his or her actions are appropriate or not and if those actions are considered bullying; if athletes perceive them to be such, they are.

\section{Application}

It is clear that not all coaches perceive and define inappropriate and bullying actions in the same way. It is therefore incumbent upon coaching education programs in colleges and universities, coaching associations (high school coaching 
associations), and sport related organizations (NFHS) to more thoroughly help coaches understand which coaching practices are unacceptable and should not be used. Granted, some of these actions are difficult to interpret. For example, what is a dirty look meant to hurt? A coaches' glance at an athlete may be interpreted in different ways by different athletes, and certainly different from what a coach intended. Do we simply prevent this by telling coaches not to look at athletes? Of course, that is not the answer.

What it comes down to is awareness. Coaches must become aware that certain words and actions carry various meanings and are understood differently by different people. Further, coaches must make every effort to listen to their athletes and eliminate or redefine those actions that are blatantly inappropriate. For example, throwing something at an athlete. Just do not do that. Problem solved.

\section{Conclusion and Further Study}

From this study, researchers gained insight into coaches' use of what might be considered inappropriate coaching practices, their thoughts regarding if they believe an action is an inappropriate coaching action, and if they consider it bullying. Coaches and athletes certainly observe, feel, and value what they experience in different ways. A coach may look at an athlete in a certain way and think nothing of it while the athlete is interpreting the look as intentionally hurtful. A further study needs to determine if athletes think the listed actions are inappropriate and considered bullying with comparisons made to what coaches think.

Are there accepted different teaching/coaching behaviors from a classroom to a practice field or gym? Is it accepted that one can make critical comments meant to hurt someone in a sport setting but not in a classroom? Further research should investigate if coaches believe this difference exists and if it holds true.

\section{References}

Alexander K, Stafford A, Lewis R (2011) The experiences of children participating in organised sport in the UK: summary report. Edinburgh: The University of Edinburgh, NSPCC Child Protection Research Centre.

American Educational Research Association (2013) Prevention of bullying in schools, colleges, and universities: research report and recommendations. Washington, DC: American Educational Research Association.

Benbow DH (2021, January 20) Toxic abuse alleged inside Purdue-Fort Wayne women's basketball: 'it was brutal'. Indy Star.

Burns GN, Jasinski D, Dunn SC, Fletcher D (2012) Athlete identity and athlete satisfaction: the nonconformity of exclusivity. Personality and Individual Differences 52(3): 280284.

Dominteanu T (2011) The significance of the coach-athlete relationship. Indian Journal of Applied Research 4(7): 512-513.

Fraser-Thomas JL, Côté J, Deakin J (2005) Youth sport programs: an avenue to foster 
positive youth development. Physical Education and Sport Pedagogy 10(1): 19-40.

Gearity B (2012) Poor teaching by the coach: a phenomenological description from athletes' experience of poor coaching. Physical Education and Sport Pedagogy 17(1): 79-96.

Gearity B, Thompson MA (2011) Athletes' experiences of psychological effects of poor coaching. Psychology of Sport and Exercise 12(3): 213-221.

Haber JD (2004) Bully-spotter: what is bullying in sports? www.respectu.com.

Jowett S, Cockerill IM (2003) Olympic medallists' perspective of the athlete-coach relationship. Psychology of Sport and Exercise 4(4): 313-331.

Moen F, Giske R, Høigaard R (2015) Coaches' perceptions of how coaching behavior affects athletes: an analysis of their position on basic assumptions in the coaching role. International Journal of Learning, Teaching and Educational Research 11(1): 180-199.

Pao M (2020, August 7) Texas Tech fires top women's basketball coaches amid abuse and allegations. NPR.

Poczwardowski A, Barott JE, Jowett S (2006) Diversifying approaches to research on athlete-coach relationships. Psychology of Sport and Exercise 7(2): 125-142.

Ronkainen H, Ryba TV (2019) Developing narrative identities in youth pre-elite sport: Bridging the present and the future. Qualitative Research in Sport 12(2): 1-15.

Ronkainen NJ, Kavoura A, Ryba TV (2016) A meta-study of athletic identity research in sport psychology: current status and future directions. International Review of Sport and Exercise Psychology 9(1): 45-64.

Shields DL, Bredemeier BL, LaVoi NM, Power FC (2005) The sport behavior of youth, parents, and coaches: the good, the bad, and the ugly. Journal of Research in Character Education 3(1): 43-59.

Solari C (2021, May 19) Detroit Mercy women's basketballs AnnMarie Gilbert, AD address allegations, violations. Detroit Free Press.

Strand B, Brotherson S, Docheff D, Gorman S (2017) Athletes' recollection of inappropriate behaviors by their high school sport coaches. The International Journal of Sport and Society 8(4): 41-55.

Swigonski NL, Enneking BS, Hendrix KS (2014) Bullying behavior by athletic coaches. Pediatrics 133(2): e273-275.

Turnnidge J, Côté J, Hancock DJ (2014) Positive youth development from sport to life: Explicit or implicit transfer? Quest 66(2): 203-217.

Vella S, Oades L, Crowe T (2011) The role of the coach in facilitating positive youth development: moving from theory to practice. Journal of Applied Sport Psychology 23(1): 33-48.

Vierimaa M, Erickson K, Côté J, Gilbert W (2012) Positive youth development: a measurement framework for sport. International Journal of Sports Science \& Coaching 7(3): 601-614.

Wimbley R, Komer D (2021, January 21) Detroit Mercy cancels women's basketball season after abusive coach allegations surface. FOX 2 Detroit.

Wolff A (2015, September 29) Is the era of abusive college coaches finally coming to an end? Sports Illustrated.

Yukhymenko-Lescroart MA, Brown ME, Paskus TS (2015) The relationship between ethical and abusive coaching behavior and student-athlete well-being. Sport, Exercise, and Performance Psychology 4(1): 36-49. 